\title{
MENGELOLA PERBEDAAN MENJADI SEBUAH KEKAYAAN: SUATU ANALISIS TEKS KOLOSE 3:12-17
}

\author{
Manase Gulo \\ Sekolah Tinggi Teologi Arastamar Bengkulu \\ manasegulo@sttab.ac.id
}

\begin{abstract}
Success in making a difference into wealth is a longing for every human being in general and for believers in particular. Everyone longs for unity. However, the reality of conflict often occurs both within the family, in the church, and in the life of the nation. One of the causes of conflict is due to not being able to manage differences. The differences in question are differences in religion, ethnicity, culture, education, and so on. If these differences are not managed properly, conflicts will continue to exist both within the family, in the church, and in the life of the nation. Seeing the situation as described above, a theory is needed on how to manage differences into wealth. This article will provide a theory on how to manage the differences to become wealthy. This theory is an analysis of Colossians 3: 12-17.

Keywords: $\quad$ Managing Difference, Wealth, Analysis, Colossians 3: 12-17

Abstraksi: Keberhasilan menjadikan perbedaan menjadi sebuah kekayaan merupakan kerinduan setiap umat manusia pada umumnya dan orang percaya pada khususnya. Setiap orang merindukan adanya kesatuan. Namun, realitas yang terjadi konflik sering terjadi baik di dalam keluarga, di dalam bergereja maupun di dalam kehidupan berbangsa. Salah satu penyebab adanya konflik dikarenakan tidak mampu mengelola perbedaan. Perbedaan yang dimaksud adalah perbedaan agama, suku, budaya, pendidikan dan lain sebagainya. Bila perbedaan ini tidak dikelola dengan baik, maka konflik terus ada baik di dalam keluarga, di dalam bergereja maupun di dalam kehidupan berbangsa. Melihat situasi seperti yang dipaparkan di atas, sangat diperlukan teori bagaimana mengelola perbedaan menjadi sebuah kekakayaan. Artikel ini akan memberikan sebuah teori bagaimana cara mengelola perbedaan menjadi sebuah kekayaan. Teori ini merupakan analisis dari Kolose 3:12-17.
\end{abstract}

Kata Kunci: $\quad$ Mengelola Perbedaan, Kekayaan, Analisis, Kolose 3:12-17

\section{PENDAHULUAN}

Perbedaan ini menjadi salah satu sumber konflik. Perbedaan dapat menyebabkan terjadinya konflik yang dalam kehidupan keluarga, bergereja dan berbangsa. Realitas di Indonesia perbedaan agama telah menyebabkan konflik di beberapa tempat yang berujung pada pembatasan beribadah dan pembakaran tempat ibadah. Menurut penelitian Rusmin Tumanggor, Jaenal Aripin, dan Iman 
Soeyouti tentang dinamika konflik etnis dan agama di lima wilayah Indonesia menyimpulkan, penyebab konflik dikarenakan adanya kesenjangan sosial ekonomi, perilaku antar etnis dan keberpihakkan aparat dalam menyelesaikan kerusuhan. ${ }^{1}$ Tito Karnavian pada waktu menjadi kepala Kepolisian Negara Republik Indonesia menyampaikan bahwa penyebab konflik di Indonesia adalah karena ketidakadilan ekonomi, masalah lingkungan dan kesenjangan sosial serta pelanggaran hak azasi manusia, temasuk hak untuk berpartisipasi urusan politik. ${ }^{2}$ Alasan lain adalah penghinaan atas keyakinan (agama) dan suku tertentu menjadi penyebab konflik yang cukup dominan. ${ }^{3}$

Konflik tidak hanya dalam kehidupan berbangsa dan bernegara, namun juga terjadi di dalam kehidupan bergereja. Salah satu penyebabnya karena identitas suku yang menyebabkan perpecahan gereja dalam beberapa gereja anggota PGI. ${ }^{4}$ Hal senada diungkapkan Van den End bahwa penyebab konflik di tubuh gereja akibat unsur kesukuan atau kedaerahan. ${ }^{5}$ Perbedaan kesukuan ini kalau tidak dikelola dengan baik akan menimbulkan konflik yang berkepanjangan di dalam bergereja.

Selain konflik berbangsa dan bergereja, dalam kehidupan rumah tangga seringkali muncul konflik antara suami dengan istri, salah satu penyebabnya adalah karena perbedaan latar belakang, keluarga, pendidikan, budaya, kebiasaan dan perbedaan lainnya. Senada dengan pernyataan ini Sipayung juga mengatakan

1 Tim Penyusun, Membangun Kedaulatan Bangsa Berdasarkan Nilai-nilai Pancasila: Pemberdayaan Masyarakat Dalam Kawasan Terluar, Terdepan, dan Tertinggal (Yogyakarta: Pusat Studi Pancasila, 2015), 191.

2 Tito Karnavian, Top Secret Membongkar Konflik Poso (Jakarta: Gramedia, 2008), 75.

${ }^{3}$ Karnavian, 75.

${ }^{4}$ Christian De Jong, Menuju Kesaan Gereja (Jakarta: BPK Gunung Mulia, 2006), 87.

5 Van den End, Ragi Carita (Jakarta: BPK Gunung Mulia, 2006), 357. 
setiap pasangan suami istri pasti mengalami konflik karena memang setiap orang berbeda sehingga hal ini menciptakan pergesekan di antara suami istri. ${ }^{6}$

Perbedaan tidak bisa dihindari, karena itu perbedaan harus dikelola dengan baik serta menjadikannya sebuah kekayaan, baik dalam kehidupan berkeluarga, bergereja dan berbangsa. Bagaimana mengelola dan menjadikan perbedaanperbedaan menjadi sebuah kekayaan? Rasul Paulus dalam tulisannya kepada Jemaat di Kolose yang sedang mengalami permasalahan karena ada perbedaan pengajaran dan pemahaman, memberikan sebuah solusi dalam Kolose 3: 12-17. Solusi dari Rasul Paulus itulah yang penulis juga akan gunakan untuk menjawab problematika tentang perbedaan.

\section{METODE}

Metode yang digunakan dalam penulisan artikel ini adalah metode eksegesis dengan pendekatan kualitatif. Penggunaan metode tersebut mengingat bahwa tujuan dari penelitian ini adalah untuk mendeskripsikan tentang landasan teori dari Kolose 3: 12-17. Penelitian ini berusaha menjelaskan apa adanya sesuai dengan konteks Alkitab. Metode ini menekankan penggalian teks yakni berusaha menjelaskan beberapa teks bahasa asli yaitu bahasa Yunani dan juga memperhatikan latar belakang masalah saat itu untuk memahami maksud yang sesungguhnya. Penulis juga menggunakan metode induksi artinya menarik kesimpulan dari yang khusus untuk diterapkan ke hal-hal yang umum.

${ }^{6}$ Hendra Sipayung, Menantu VS Mertua, Trik Ampuh membina hubungan baik antara menantu dan Mertua (Jakarta: Gramedia, 2010), V. 


\section{HASIL}

Teori mengelola perbedaan menjadi sebuah kekayaan bagi keluarga, bergereja dan bangsa, dapat ditemukan melalui pengajaran Paulus kepada jemaat di Kolose. Langkah awal mengelola perbedaan menjadi sebuah kekayaan adalah masing-masing orang menjadi manusia baru. Setelah masing-masing orang menjadi manusia baru, maka dalam diri setiap orang mempraktekkan kedelapan teori yang diajarkan Paulus dalam Kolose 3: 12-17. Inilah teori yang yang sangat baik dalam membangun kesatuan di tengah-tengah perbedaan. Teori tersebut adalah mengenakan belas kasihan, mengenakan kemurahan, mengenakan kerendahan hati, mengenakan kelemahlembutan, mengenakan kesabaran, mengenakan pengampunan, memerintah dengan damai sejahtera dan mengenakan perkataan Kristus.

\section{PEMBAHASAN}

Memahami makna yang terkandung dalam Kolose 3:12-17, penulis lebih dahulu menguraikan Variasi Teks, latar belakang teks dan istilah manusia baru.

\section{Variasi Teks Kolose 3:12-17}

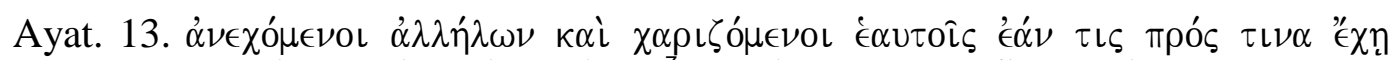

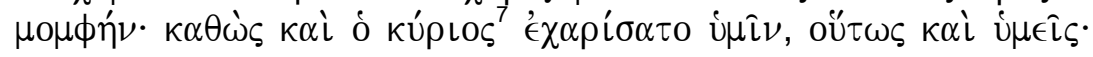

${ }^{7}$ Kolose 3:15 terdapat variasi teks dengan memberikan tanda (C) pada kata ku,rioj. Naskah yang menggunakan kata ku,rioj adalah naskah Alexandrinus abad ke-5, Vaticanus abad ke-4, Cambridge abad ke-5, Ephraemi Rescriptus pada abad ke-4, Utrech dan Cambridge pada abad ke-9, Boernerianus abad ke-9. Sedangkan naskah yang menggunakan kata Cristoj adalah naskah Sinaiticus abad ke-4, Ephraemi Rescriptus, Claromontanus abad ke-6, Athos abad ke-8. Beberapa Unsial juga menggunakan kata Cristoj yakni 0750150681104256263365424436459124113191573185218811912196221272200 , Naskah Byzantium, Paris abad dan Moskow ke-9, Regius dan Roma abad ke-9, naskah Latin tua, naskah Siria, Versi Koptik dialek Sahidi dan Bohairi, Naskah Georgia, Slavia, Clement Chrysostom Nilus Theoder, Ambrosiaster Jerome. Selain ku,rioj dan Cristoj ada juga yang menggunakan kata Qeoj en kristw yakni versi Armenia dan Vulgata. Perbedaan penggunaan istilah yang digunakan oleh naskah-naskah tua di atas, tidak menunjukkan perbedaan makna yang signifikan karna semua istilah-istilah yang digunakan menunjuk kepada Yesus Kristus bahwa mengampuni seperti Kristus mengampuni umatNya. 


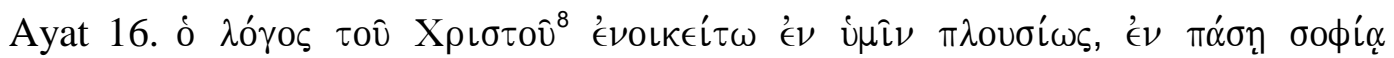

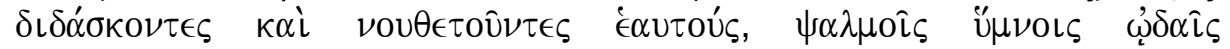

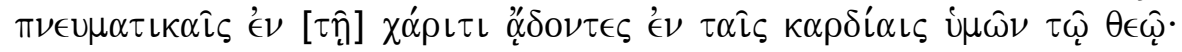

\section{Konteks}

Kolose 3: 12-17 adalah sebuah teori yang diajarkan Paulus kepada jemaat Kolose. Saat itu jemaat di Kolose sedang mengalami permasalahan karena ada perbedaan pengajaran dan pemahaman. Paulus mengajarkan setelah menjadi manusia baru milikilah kesatuan. Ayat 10-11 adalah perintah untuk tidak membeda-bedakan orang Yunani dan orang Yahudi, tidak membedakan orang bersunat dan orang tidak bersunat, tidak membedakan orang Barbar dan orang Skit, tidak membedakan budak dan orang merdeka. Paulus berkata dalam ayat 510 tinggalkan hidup lama seperti percabulan, kenajisan, hawa nafsu, nafsu jahat dan juga keserakahan, yang sama dengan penyembahan berhala, amarah, geram, kejahatan, fitnah, dan kata-kata kotor, saling mendustai.

Ayat 10-11 menekankan bahwa setelah menjadi manusia baru tidak ada lagi sikap untuk membeda-bedakan suku, ras, agama, budaya dan golongan tertentu. ${ }^{9}$ Paulus menekankan di sini tidak ada yang inferioritas diantara suku

8 Kolose 3:16 terdapat variasi teks dengan memberikan tanda (A) pada kristou/. Naskah yang menggunakan kata kristou/ adalah naskah Chester Beatty dan Ann Arbor, Mich, naskah Sinaiticus abad ke4, naskah vaticanus, Naskah ephraemi Rescriptus abad ke-5, Bezae Cantabrigiensis abad ke-5, naskah Cabridge abad ke-9, Naskah Boernerianus abad ke-9. Beberapa miniskul juga menggunakan kata kristoul yakni 01506812563654241319157317391852188119122200 2464, naskah Byzantium, naskah Paris, Moskow, Regius, Roma, naskah Wolfenbuttel, versi vulgata, Coptik, Armenia, Georgia, Slavia, Chrysostom; Ambrosiaster Pelagius Speculum. Naskah yang tidak menggunakan kata kristou/ lalu menggunakan kata Qeou/ adalah naskah Alexandrinus abad ke-4, Naskah Ephraemi Rescriptus abad ke-5. Beberapa minuskul juga menggunakan kata Qeou/ yakni 33104263436459124119626014759359911541365 1439. Versi Vulgata, Theodore, Ambrose, Augustine, Quodvultdeus juga menggunakan kata Qeou/. Varian ketiga adalah kata Kuriou. Naskah yang mendukung adalah naskah Sinaitikus, Naskah Washington, dan miniskul 1175, 2127, versi Coptik dan Clement. Kata kristou/, Qeoul, Kuriou menunjuk kepada pribadi yang llahi yang pribadi Tuhan. karena itu tidak ada perbedaan makna yang signifikan.

${ }_{9}$ Robert G. Bratcher dan Eugene A, Penafsiran Alkitab: Surat-surat Paulus kepada Jemaat di Kolose dan Filemon (Jakarta: LAl, 2014), 7. 
yang satu dengan suku yang lain atau antara laki-laki dan perempuan. ${ }^{10}$ Artinya semua manusia di mata Allah sama. Informasi ini ditemukan dari pernyataan Paulus tidak ada orang Yunani dan orang Yahudi. Bangsa Yunani mewakili bangsa-bangsa bukan Yahudi secara keseluruhan. Bangsa Yahudi dan Bangsa Yunani telah menjadi satu sejak menjadi manusia baru di dalam Kristus.

\section{Manusia Baru}

Langkah awal mengelola perbedaan menjadi sebuah kekayaan masingmasing orang harus menjadi manusia baru. Menurut Hoekema kelahiran baru adalah permulaan kehidupan rohani yang baru, yang ditanamkan dalam diri oleh Roh Kudus membuat bertobat dan percaya. ${ }^{11}$ Roh Kudsus membuat seseorang lahir baru dan membawa orang-orang ke dalam kesatuan yang hidup dengan Kristus, mengubah hati yang mati secara rohani, dan sekarang berkemampuan dan berkehendak untuk bertobat dari dosa, mempercayai Injil dan melayani Tuhan. Dengan menerima Yesus Kristus sebagai Tuhan dan Juruselamat akan mampu menjadi pembawa damai sejahtera bagi umat manusia. ${ }^{12}$

Jimmi Menambahkan bahwa kelahiran baru menjadi tanda bahwa seseorang memahami dan mengetahui kebenaran-kebenaran rohani yang sejati. ${ }^{13}$ Kebenaran-kebenaran yang dari Allah inilah yang diterapkan oleh setiap percaya kepada sesama. Dengan kebenaran ini pasti mampu mengelola perbedaan menjadi sebuah kekayaan. Ketika seseorang sudah dikuasai kebenaran dari Allah maka

\footnotetext{
${ }^{10}$ Peter T. O'Brien, World Biblical Commentary Colossians (Texas: Word Books Publisher, 2011), 194.

11 Hoekma Anthony, Diselamatkan oleh Anugrah (Surabaya: Momentum, 2011),133-134.

12 Wangyu Wangyu dan Robi Panggarra, "Konsep Eirene Berdasarkan Efesus 2:11-22 Dan Implementasinya Dalam Kekristenan Masa Kini," Jurnal Jaffray 8, no. 2 (1 Oktober 2010): 86-105.

13 Jimmi Kurniawan, "Kajian Eksegetikal Tentang Kelahiran Baru Menurut Yohanes 3:1-8," Jurnal Teologi Gracia Deo 1, no. 1 (Juni 2018): 1-13, http://sttbaptisjkt.ac.id/ejournal/index.php/graciadeo/article/viewFile/17/7.
} 
otomatis hidup seseorang dipimpin oleh Tuhan. Ketika hidup seseorang sudah dipimpin Tuhan, orang tersebut membawa damai sejahtera.

\section{Mengenakan Belas Kasihan}

Mengelola perbedaan menjadi sebuah kekayaan bagi keluarga, gereja dan bangsa harus mengenakan belas kasihan (ay.12). Belas kasihan sangat penting dalam mengelola sebuah konflik. Hal Ini ditekankan Paulus, jika satu orang tidak sepaham dengan lainnya, ia harus tetap mengasihi dari pada merusak reputasi

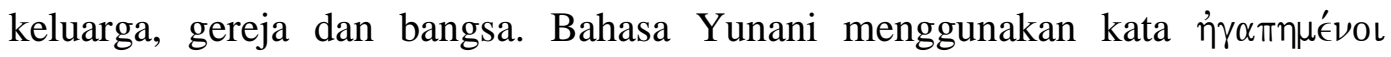
(egapemenoi) ini merupakan bentuk perfek partisip dari kata dasar $\dot{\alpha} \gamma \alpha \pi \alpha \dot{\omega} \omega$ (agapao) artinya mengasihi untuk selamanya. Henry menegaskan bahwa orangorang yang menjadi pilihan Allah, merupakan orang yang dikuduskan haruslah berprilaku sebagaimana keadaan mereka agar tidak kehilangan kekudusan mereka. ${ }^{14}$

Inti yang ditegaskan Henry adalah sebagai orang pilihan Allah dan yang telah dikuduskan harus penuh kasih terhadap semua orang atau harus mengenakan belas kasihan. Menurut Guthrie belas kasihan yang dimaksud adalah kepentingan diri ditiadakan, orang harus bersikap ramah terhadap orang lain. ${ }^{15}$ Kasih agapao yaitu kasih seperti kasih Tuhan Yesus yang rela berkorban bahkan rela mati di kayu salib untuk menebus umat manusia. Kasih yang seperti ini adalah kasih yang tanpa pamrih.

Prinsip belas kasihan, Pertama, mempersatukan (ay.14). Kata kenakanlah kasih melebihi kebaikan yang disebut kebajikan, sebab kasih berfungsi sebagai

14 Matthew Henry, Tafsiran Surat Galatia, Efesus, Filipi, Kolose, 1 dan 2 Tesalonika, 1 dan 2 Timotius, (Surabaya: Momentum, 2015), 398.

15 Donald Guthrie, Teologi Perjanjian Baru, vol. 3 (Jakarta: BPK Gunung Mulia, 2009), 280. 
pengikat dan. menyatukan semua kebajikan. Artinya kasih adalah pengikat dari setiap perbedaan. Setiap orang bila dikenakan belas kasihan, maka semua kebajikan akan dipersatukan sehingga terlihat indah dan harmonis yang menunjukkan kedewasaan rohani yang pastinya mempertahankan keseimbangan dan pertumbuhan hidup. Kasih adalah kuasa pengikat yang merangkul seluruh tubuh kristen bersama. ${ }^{16}$

Barclay menuliskan bahwa kecenderungan setiap orang adalah ingin berpisah atau memisahkan diri. Kasih adalah suatu ikatan yang akan merangkul dalam persekutuan yang tak dapat diputuskan. ${ }^{17}$ Pernyataan ini meyakinkan bawah kasih yang agapao memiliki kuasa mempersatukan perbedaan-perbedaan. Kasih itu membuat setiap orang saling menghargai dan menghormati perbedaan. Tidak hanya itu, kasih juga memiliki kuasa untuk mengikat kesatuan yang telah ditetapkan, misalnya dalam kehidupan berbangsa ada rumusan pancasila yang mempersatukan perbedaan, dalam kehidupan bergereja ada tubuh Kristus yang mempersatukan perbedaan-perbedaan dan dalam kehidupan berkeluarga ketetapan Allah yaitu satu daging yang mempersatukan perbedaan. Rumusan pancasila, tubuh Kristus dan satu daging diikat dalam satu kasih.

Kedua, menyempurnakan (ay.14). Kasih yang menyempurnakan adalah kasih yang dapat mengatasi semua sakit hati dan prasangka. Hal ini dapat dilakukan dalam kehidupan berbangsa, bergereja dan di dalam kehidupan berkeluarga dengan cara mengampuni sesama seperti Kristus telah mengampuni. Menerapkan prinsip ini membuat hidup dalam damai dengan kerukunan dengan sesama. Kemampuan dalam menerapkan prinsip ini karena telah dipilih dan harus

16 William Barclay, Pemahaman Alkitab Setiap Hari, Surat Filipi, Kolose, 1 dan 2 Tesalonika (Jakarta: BPK Gunung Mulia, 2006), 21.

17 Barclay, 21. 
berjuang bersama-sama untuk membangun tubuh Kristus, membuatnya menjadi satu melalui ikatan kasih yang sempurna.

\section{Mengenakan Kemurahan}

Teori yang kedua dalam mengelola perbedaan menjadi sebuah kekayaan adalah mengenakan kemurahan (ay. 12). Kata Yunani yang digunakan untuk kata kemurahan adalah $\sigma \pi \lambda \alpha^{\prime} \gamma \chi \nu \alpha$ (splagchna) dari kata dasar $\sigma \pi \lambda \alpha^{\prime} \gamma \chi \nu 0 \nu$ (splagchnon) artinya batin yang paling dalam dan lubuk hati. Menurut Dunn $\sigma \pi \lambda \alpha^{\prime} \gamma \chi \nu \alpha$ (splagchna) menunjukkan sesuatu yang sangat terasa yang dimaksud adalah kasih sayang sepenuh hati. ${ }^{18}$ Kata kemurahan memiliki arti sebagai tindakan baik dan benar yang dilakukan untuk orang lain atau untuk melayani Tuhan dengan motivasi yang benar, karena telah menerima kemurahan (keselamatan) dari Tuhan, sehingga tindakan yang dilakukan penuh dengan sukacita agar orang lain hal yang sama.

Kemurahan memampukan memiliki hati yang selalu bersedia memahami, mengampuni, mengalah, rela berkorban, berbagi berkat, memberi diri demi kebaikan orang lain, rindu untuk selalu bisa memberikan pelayanan bagi Tuhan dan sesama dengan azas kasih, kerendahan hati dan peka terhadap kebutuhan orang lain. Semua buah dari kemurahan tersebut diberikan dan dilakukan hanya untuk kemuliaan Allah, sebagai tanda kasih kepada Dia yang sudah begitu mengasihi kita. Dalam Lukas 7: 37-38 bentuk kemurahan terlihat pada kasus perempuan berdosa yang meminyaki kaki Yesus yang menunjukkan kasih dengan sepenuh hati.

18 James D. G. Dunn, The Epistles To The Colossians and to Philemon A Commentary on the Greek Text, (Michigan: Baker Book House Publisher, 1996), 228 
Kemurahan yang dimaksud hanya menolong dengan sepenuh hati. Orangorang pilihan Allah harus menunjukkan kemurahan, sopan santun kepada semua orang, karena tujuan injil bukan hanya melembutkan pikiran manusia, tetapi untuk memperindah, serta mempererat persahabatan di antara manusia selain juga memperdamaikan manusia dengan Allah. ${ }^{19}$ Kemurahan adalah sifat yang dimiliki

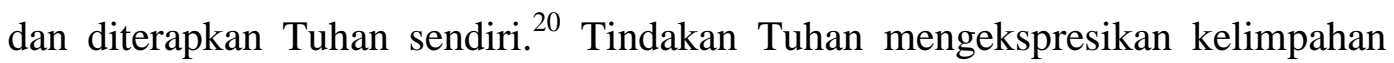
kekayaan-Nya kepada orang-orang pilihan sebagai ciptaan-Nya yang mulia. ${ }^{21}$ Kelimpahan atau kemurahan yang dimaksud adalah karya keselamatan.

Kemurahan Tuhan dapat lihat dari Alkitab yakni Pertama, dilukiskan sebagai sesuatu yang berlimpah-limpah (Bil. 14: 18; Yes. 54: 7), kaya (Ef. 2: 4), Besar (Neh. 9: 27; Rat. 3: 32), Teguh (Yes. 55: 3; Mikha, 7: 20), kekal, ( 1Taw. 16: 34; Mzm. 89: 29; 106: 1; 136: 1), selalu baru tiap pagi (Rat. 3: 23), Kedua, dinyatakan oleh Kristus (Luk. 1: 78), di dalam Keselamatan (Tit. 3: 5), kepada umatNya (Ul. 32: 43; 1Raj. 8: 23), atas orang-orang yang takut akan Dia (Maz. 103: 17; Luk. 1: 50). Ketiga, satu dasar pengharapan (Mzm. 130: 7; 147: 11). Keempat, satu dasar pengharapan (Mzm. 52:9).

\section{Mengenakan Kerendahan hati}

Istilah kerendahan hati (ay.12) dalam bahasa Yunani $\tau \alpha \pi \epsilon \iota \nu \circ \rho \circ \sigma u ́ \nu \eta \nu$

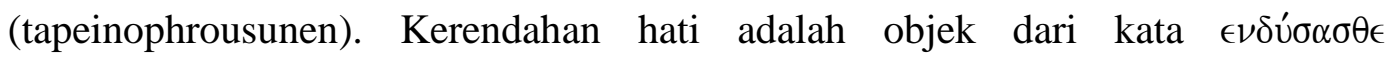
(endusasthe). Kerendahan hati wajib dimiliki semua orang dalam mengelola perbedaan menjadi sebuah kekayaan, hal Ini merupakan pikiran yang menyenangkan Allah. Brien mempertegas bahwa kerendahan hati menunjukkan

\footnotetext{
${ }^{19}$ Henry, Tafsiran Surat Galatia, Efesus, Filipi, Kolose, 1 dan 2 Tesalonika, 1 dan 2 Timotius, ,398.

20 O'Brien, World Biblical Commentary Colossians, 199.

21 O'Brien, 199.
} 
sikap penyangkalan diri. ${ }^{22}$ Penyangkalan diri yang dimaksud adalah bahwa di dalam diri manusia yang telah dilahirkan baru oleh Tuhan, semua yang ada padanya adalah hanya anugerah Tuhan, dengan demikian tidak ada alasan untuk menyombongkan diri. Dalam literatur Yunani istilah kerendahan hati biasanya ada perasaan merendahkan, kelemahan dan keburukan yang memalukan. ${ }^{23}$ Namun bagi orang yang telah menjadi manusia baru kerendahan hati adalah hal yang menyenangkan Allah. Henry mengatakan: mengenakan kerendahan hati berarti menundukkan diri terhadap orang-orang yang lebih tinggi dari kita, dan membumi dengan orang-orang yang lebih rendah dari kita, tidak hanya sikap tetapi pikiran juga harus rendah hati. ${ }^{24}$ Yesus berkata belajarlah padaku karena aku lemah lembut dan rendah hati (Mat. 11: 29). Tuhan sendiri telah memberikan teladan bagaimana sikap rendah hati yaitu ketika Ia berinkarnasi menjadi manusia dan bahkan mengambil rupa seorang hamba (Flp. 2: 5-11; Yoh. 1: 14). Kerendahan hati merupakan sifat dari Tuhan Yesus yang adalah pemimpin sepanjang abad. Sifat pemimpin seperti ini membawa damai sejahterah bagi umat manusia. Hal yang sama juga bisa terjadi dalam kehidupan berbangsa, bergereja dan dalam keluarga apabila setiap pemimpin memiliki sifat kerendahan hati.

Bagaimana seseorang belajar kerendahan hati? Pertama, seseorang dapat menjadi rendah hati dengan mempertimbangkan hubungan dia dengan Allah dan dengan sesamanya (Ams. 6:1-5). Istilah ibrani rendahkanlah dirimu menggunakan kata hithrappes arti harafiah injak-injak dirimu. Kandungan makna ini menunjukkan bahwa manusia hendaknya membuang sikap gengsi, mengakui kesalahan, luruskanlah masalah dan minta pengampunan. Yesus menasehati agar

22 O'Brien, 200.

23 O'Brien, 200.

24 Henry, Tafsiran Surat Galatia, Efesus, Filipi, Kolose, 1 dan 2 Tesalonika, 1 dan 2 Timotius, 398. 
seseorang merendahkan diri dihadapan Allah seperti seorang anak kecil (Mat. 18: 4; 23: 12). Kedua, belajar kerendahan hati karena direndahkan melalui pengalaman. Tuhan memberi tahu Israel bahwa Ia merendahkan hati mereka dengan membuat mereka mengembara selama 40 tahun di padang belantara untuk menguji mereka, guna mengetahui apa yang ada dalam hati mereka dan membuat mereka mengerti bahwa bukan dengan roti saja manusia hidup, melainkan dengan setiap pernyataan dari mulut Allah (Ul. 8: 2,3). Banyak orang Israel tentu mengambil hikmat dari pengalaman pahit dan memperoleh kerendahan hati (bdk. Im. 26: 41; 2Taw. 7: 14; 12: 6,7).

Manfaat kerendahan hati adalah Pertama, menyenangkan Allah. Kerendahan hati sangat berharga di mata Tuhan. Meskipun Allah tidak berhutang kepada manusia, dengan kebaikan hati yang tidak selayaknya diperoleh Ia siap memperlihatkan belas kasihan dan perkenan kepada orang-orang yang merendahkan diri dihadapan-Nya. Kedua, menghasilkan kedamaian. Kerendahan hati memajukan kedamaian. Orang yang rendah hati tidak bertengkar dengan saudaranya demi menegakkan apa yang menjadi haknya. Rasul Paulus menyatakan meskipun ia bebas melakukan segala hal, ia hanya melakukan hal-hal yang membina, dan jika hati nurani seorang saudara terganggu oleh tindakan yang ia lakukan, ia tidak akan melakukan hal itu (Rm. 14: 19-21; 1 Kor. 8: 9-13; 10: 23-33). Ketiga, dikasihi, ditinggikan / dipromosikan Tuhan pada waktunya. Allah menentang orang yang angkuh, tetapi kepada orang yang rendah hati ia memberikan kebaikan hati yang tidak selayaknya diperoleh (Yak. 4: 6; 1Ptr. 5: 5). Keempat, mendapat Bimbingan dari Tuhan. Orang yang merendahkan diri di hadapan Allah akan dibimbing oleh Tuhan. Ketika bangsa Israel pulang dari 
Babel ke Yerusalem, Ezra tidak meminta pengawalan Militer kepada raja Persia sebab hal itu sama halnya dengan mengandalkan manusia, tetapi Ezra mengumumkan puasa agar merendahkan diri di hadapan Tuhan dan Tuhan mendengarkan serta memberikan mereka perlindungan dari serangan musuh sehingga perjalanan yang berbahaya itu berhasil (Ezr. 8: 1-14, 21-32).

\section{Mengenakan Kelemahlembutan}

Kelemahlembutan adalah salah satu karakter yang dimiliki oleh setiap manusia. Kelemahlembutan ini adalah satu teori mewujudkan perbedaan menjadi sebuah kekayaan di tengah dunia yang multikultural. Orang yang lemah lembut adalah orang yang memiliki kekuatan atau kelebihan, namun dapat menguasai diri dan mengontrol kekuatannya; tidak menyalahgunakan kekuatan dan kuasa yang dimiliki namun dapat memakai kekuatan dengan benar dan bijaksana. Hal ini dipertegaskan oleh Henry bahwa kelemahlembutan terhadap orang yang membangkitkan amarah dan menyakiti akan menolong untuk bijaksana dan membungkam amarah. ${ }^{25}$ Henry mengartikan orang yang lemah lembut adalah orang yang mampu membungkam amarah sendiri, dan sabar menanggung amarah orang lain. Dengan demikian orang yang lemah lembut adalah orang yang mampu mengendalikan diri, menahan emosi, berkomunikasi dengan halus, rendah hati, bersikap sopan dan penuh pertimbangan.

Brien berpendapat bahwa orang yang lemah lembut adalah orang yang penuh pertimbangan untuk orang lain dan kemauan untuk membebaskan hak orang lain. ${ }^{26}$ Dunn menegaskan bahwa kelemahlembutan adalah kekuatan untuk

25 Henry, 398-399.

26 O'Brien, World Biblical Commentary Colossians, 201. 
berhadapan dengan konflik. ${ }^{27}$ Kekuatan yang dimaksud adalah kemampuan berinteraksi dengan orang yang sedang konflik, yang pada akhirnya mendatangkan damai sejahtera. Karena mampu berinteraksi dengan sopan, rendah hati dan penuh pertimbangan. Alkitab menjelaskan arti kelemahlembutan yakni: Pertama, tunduk kepada Tuhan. Salah satu tokoh Alkitab Daud berusaha agar hidupnya berkenan kepada Tuhan. Musa disebut lemah Lembut karena ia dengan rendah hati menundukkan dirinya pada kehendak Allah. Kedua, mudah dibentuk dan diajar. Orang yang lemah lembut tidak mudah tersinggung dan dengan senang hati menerima teguran ataupun kritik (Yak. 1: 21). Ketiga, mampu mempertimbangkan dan menghargai pendapat orang lain (Ams. 15: 4a).

Kelemahlembutan ditunjukkan oleh Tuhan dalam menahan murka-Nya atas manusia yang berdosa, dan menunjukkan murka-Nya kepada Diri-Nya sendiri di dalam dan melalui Yesus Kristus. Yesus Kristus selama di dunia telah mempraktekan sikap yang lemah lembut terhadap manusia berdosa misalnya pada saat berada di kayu salib ada tujuh perkataan yang diucapkan, tidak ada perkataan yang mengutuk orang yang menganiaya-Nya dan membunuh-Nya, sebaliknya perkataan-Nya memberkati dan menguatkan orang yang percaya kepada-Nya. Dampaknya membawa orang-orang yang belum percaya menjadi percaya kepadaNya (bdg. Kol. 6: 1-2).

\section{Mengenakan Kesabaran}

Kesabaran dalam bahasa Yunani diterjemahkan dari dua kata yakni

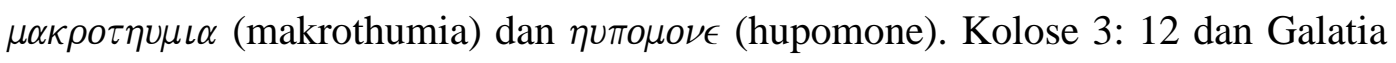

${ }^{27}$ J.D.G. Dunn, The Epistles to the Colossians and to Philemon: A Commentary on the Greek Text, The new international Greek Testament commentary (W.B. Eerdmans, 1996), 229. https://books.google.co.id/books?id=j3F0oypUqZoC. 
5: 22 menuliskan kata $\mu \alpha \kappa \rho о \tau \eta \nu \mu \iota \alpha$ (makrothumia), yang terdiri dari dua kata yaitu makro dan thumia. Makro artinya lama dan thumia artinya kemarahan atau amarah. Jadi kata $\mu \alpha \kappa \rho о \tau \eta \nu \mu \iota \alpha$ (makrothumia) secara literal artinya lama/lambat untuk marah, atau tahan menderita. Kesabaran adalah kemampuan untuk menangani orang-orang yang sulit dalam waktu yang lama sebelum menjadi marah, bertekun dengan sabar dan berani, sabar dalam menanggung perlawanan dan luka dari orang lain, lambat dalam membalas dan lambat untuk menghukum. Konsep kesabaran inilah yang perlu dilakukan umat Kristen dalam keadaan yang sulit. Kata hupomone artinya bersabar terhadap hal-hal yang tidak menyangkut orang tetapi menyangkut keadaan. Kesabaran adalah kualitas yang tidak menyerah kepada keadaan atau tunduk di bawah penderitaan dan berkaitan dengan pengharapan bahwa keadaan akan menjadi lebih baik (1Tes. 1: 3).

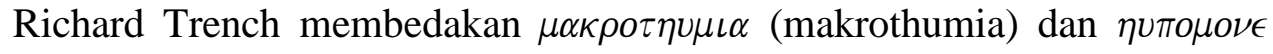
(hupomone). Kata $\mu \alpha \kappa \rho o \tau \eta \nu \mu \iota \alpha$ (makrothumia) menunjuk kepada kesabaran dengan hormat kepada orang lain, sedangkan $\eta \cup \pi o \mu o \nu \epsilon$ (hupomone) kesabaran dengan hormat kepada keadaan. ${ }^{28}$ Seseorang $\mu \alpha \kappa \rho о \tau \eta \nu \mu \iota \alpha$ (makrothumia) jika dia harus berhubungan dengan orang yang melukai dan tidak membiarkan dirinya terprovokasi oleh mereka atau meledak dalam amarah (2Tim. 4: 2). Sedangkan

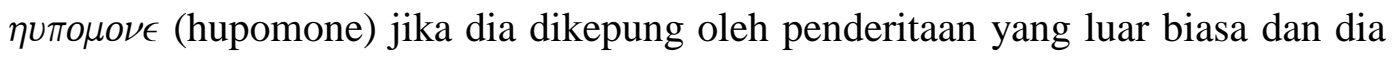
bertahan serta tidak kehilangan hatinya yang berani. Inti dari $\mu \alpha \kappa \rho о \tau \eta u \mu\llcorner\alpha$ (makrothumia) dalam Kolose 3:12 adalah sabar terhadap orang lain. Matthew 219.

${ }^{28}$ Richard Chenevix Trench, Synonyms Of The New Testament (London: Ted Hildebrant, 2006), 
Henry menjelaskan bahwa kesabaran itu sangat berhubungan dengan kasih. ${ }^{29}$ Menerapkan sifat $\mu \alpha \kappa \rho о \tau \eta u \mu\llcorner\alpha$ (makrothumia) adalah salah satu langkah mewujudkan damai sejahtera di dunia yang beraneka ragam konflik.

Penyebab menurunnya sifat kesabaran banyak orang karena diterapkan budaya instan oleh orang-orang postmodern. Penyebab lain yang mempengaruhi menurunnya kesabaran adalah belum dewasa karakter, masih mementingkan diri sendiri dan menuntut, tidak mampu menerima/melihat kesalahan dan ketidaksempurnaan orang lain, mudah marah, jengkel, tersinggung, iri hati dan tidak peka terhadap pembentukan Tuhan dalam hidup. Situasi ini membutuhkan $\mu \alpha \kappa \rho о \tau \eta u \mu\llcorner\alpha$ (makrothumia) untuk mengurangi konflik dalam kehidupan berbangsa, bergereja dan dalam kehidupan keluarga.

Kesabaran memiliki banyak manfaat, yaitu: pertama, kunci kemenangan dan keberhasilan. Margareth Thatcher yang dikutip Kiyosaki dalam buku sebuah judul Rich woman. pernah katakan, "saya sangat sabar, asalkan pada akhirnya saya mendapatkan apa yang saya inginkan. ${ }^{30}$ Karakter kesabaran terbentuk melalui ujian iman. Kesabaran selalu berhubungan dengan keadaan sulit, bahkan kesabaran merupakan senjata untuk mengatasi kesulitan. Kesabaran tidak muncul dengan otomatis dalam diri seseorang. Kesabaran bukan bawaan sejak lahir. Masa sulit diijinkan Tuhan terjadi dalam hidup untuk membantu menumbuhkan kesabaran dalam diri kita. Contoh nyata dalam alkitab kisah Ayub kesabaran mendatangkan berkat dan kemengangan. Kedua, membantu mengambil keputusan

${ }^{29}$ Kasih itu sabar dan kasih itu murah hati ( 1 Kor. 13:4). Banyak orang mampu bersabar untuk sementara, tetapi tidak tahan jika harus berlama-lama melakukannya. Namun harus panjang sabar, baik ketika disakiti oleh manusia maupun ketika ditegur oleh Sang Pemelihara llahi. Jika Allah saja panjang sabar terhadap kita, sekalipun membangkitkan marah-Nya begitu rupa, maka harus bersabar terhadap orang lain dalam hal-hal serupa. (Lih.: Henry, Tafsiran Surat Galatia, Efesus, Filipi, Kolose, 1 dan 2 Tesalonika, 1 dan 2 Timotius, 399.)

30 Margareth Thatcher, Buku Infestasi bagi Kaum Perempuan (Jakarta: Gramedia, 2007), 191. 
yang benar, sebab kesabaran itu menghindari pengambilan keputusan dengan tergesa-gesa, emosi yang mengakibatkan keputusan itu salah, dan kesabaran juga menjadikan lebih tenang, bijaksana dalam pengambilan keputusan dan hasilnya keputusan yang diambil adalah keputusan yang benar. Ketiga, hubungan lebih bahagia. Tidak semua persoalan harus dihadapi dengan emosi, terkadang kelembutan dan kesabaran yang akan mencairkan segala situasi yang rumit. Ketika sabar orang yang ada disekitar akan merasa nyaman dan aman. Keluarga, sahabat, bahkan pasangan akan lebih respek terhadap kita. Keempat, membuat selalu positif thinking. Sabar memang selalu tidak mudah, tapi rasa sabar akan mengajarkan untuk selalu positif thinking. Akibatnya membuat setiap masalah yang hadapi terasa lebih mudah dan tentunya bahagia.

\section{Mengenakan Pengampunan}

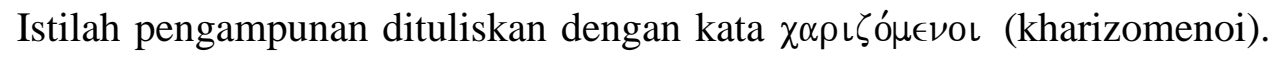
Kasus yang digunakan adalah kata kerja present partisip aktif. Bentuk partisip menunjukkan bahwa setiap orang percaya yang telah menjadi manusia baru, wajib mengenakan pengampunan dan mampu mengampuni orang yang bersalah. Sedangkan bentuk present menjukkan bahwa pengampunan itu terus menerus atau pengampunan itu seumur hidup. Brien menegaskan bahwa pengampunan harus dilakukan tanpa henti (Mat. 18:22). ${ }^{31}$

Pengampunan sangat penting diantara orang-orang pilihan Allah, yang dikuduskan dan dikasihi. Seperti halnya diantara Paulus dan Barnabas timbul perselisihan yang tajam, sehingga mereka berpisah (Kis. 15: 39), dan diantara Paulus dan Petrus (Gal. 2: 14). Namun di dalam perkara-perkara semacam itu,

31 O'Brien, World Biblical Commentary Colossians, 202. 
wajib saling mengampuni dan tidak menyimpan dendam. Dasarnya sama seperti Tuhan telah mengampuni, maka manusia wajib memperbuat demikian. Dengan merenungkan betapa banyak kesalahan sudah diampuni oleh Kristus menjadi alasan yang baik untuk mengampuni orang lain. Bahwa Kristus di dunia ini berkuasa mengampuni dosa dan menjelaskan keilahian-Nya. ${ }^{32}$ Maka dasar pengampunan Tuhan Yesus telah terlebih dahulu mengampuni segala dosa dan kesalahan dengan cara mati di kayu salib. Karena itu tidak ada alasan untuk tidak mengampuni sesama yang bersalah (Mat. 6: 14-15).

Langkah-langkah untuk mengampuni yakni memiliki sifat rendah hati melalui tindakan dan sikap saling percaya yang semakin bertumbuh, ketika manusia tidak mengampuni sesama yang bersalah damai sejahtera tidak ada dalam hidup manusia (Bdk. Mat. 6: 14-15). Syarat utama untuk mendapat kedamaian adalah mengenakan pengampunan. Prinsip pengampunan adalah pertama, mengampuni dengan kasih yang tulus. Sebab kasih itu dapat menutup dosa dan kesalahan (1Kor. 13: 4-7). Kedua, mengampuni tanpa syarat. Prinsip ini sama dengan pengampunan Tuhan (Luk. 7: 41-43). Ketiga, pengampunan itu Tiada batas. Matius 18: 22 yakni modus yang digunakan present indikatif artinya pengampunan itu 77 x 7 kali (pengampunan terus menerus atau tanpa batas). Dengan demikian pengampunan dapat menerima perbedaan-perbedaan dan memulihkan suatu hubungan yang telah rusak dengan sesama. 


\section{Memerintah Dengan Damai Sejahtera}

Kata damai sejahtera dalam bahasa Ibrani shalom, dalam bahasa Yunani eirene. ${ }^{33}$ Dalam kamus bahasa Indonesia damai sejahtera terdiri dari dua kata damai dan sejahtera. Damai diartikan tidak ada perang, tidak ada kerusuhan, aman, tentram, rukun. ${ }^{34}$ Sedangkan kata sejahtera aman sentosa dan makmur. Jadi damai sejahtera adalah keadaan dimana keadaan dunia atau sesesorang aman. Dalam Kolose 3: 12-17 damai sejahtera yang dimaksud adalah buah semangat persekutuan dan keselarasan yang harus nyata dalam diri dan persekutuan Kristen. $^{35}$

Kalimat 'hendaklah damai sejahtera Kristus memerintah dalam hatimu'

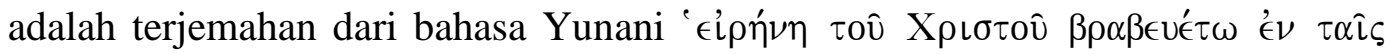

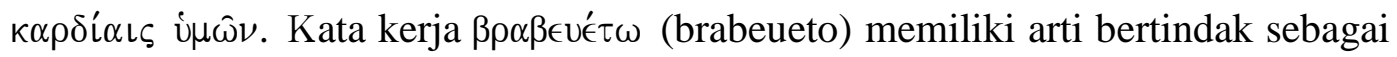
wasit, menentukan, memutuskan suatu perkara. $^{36}$ Ungkapan menjadi wasit menunjukkan bahwa saat ada perbedaan pendapat, perselisihan maka damai sejahtera Kristus menghentikan dan melerai sehingga tidak terjadi pertengkaran. Damai sejahtera yang dimaksud dalam Kolose 3: 15 damai sejahtera yang diciptakan oleh Kristus yang dihasilkan melalui penyaliban. ${ }^{37}$ Penyaliban Kristus membuat orang-orang Yahudi bukan Yahudi diciptakan menjadi satu di dalam Kristus. Perbedaan kebudayaan tidak lagi menjadi masalah tetapi menjadi kekayaan.

${ }_{33}$ Wangyu Wangyu dan Robi Panggarra, "Konsep Eirene Berdasarkan Efesus 2:11-22 Dan Implementasinya Dalam Kekristenan Masa Kini."

34 Tim Pustaka Phoenix, Kamus Besar Bahasa Indonesia (Jakarta: Media Pustaka Phoenix, 2009), 170.

${ }^{35}$ Bratcher dan A, Penafsiran Alkitab: Surat-surat Paulus kepada Jemaat di Kolose dan Filemon, 84.

${ }^{36}$ Bratcher dan A, 84. 2020).

${ }^{37}$ Witness Lee, Pelajaran Hayat Kolose, vol. 2 (Yayasan Perpustakaan Injil Indonesia (Yasperin), 
Yohanes 14: 27 menunjukkan Yesus Kristus yang menjadi inisiator untuk damai sejahtera. Yesus bukan hanya pelaku atau teladan damai sejahtera tetapi Dia sendiri yang menjadi damai sejahtera. Damai sejahtera ada di dalam diri orang percaya ketika bersatu dengan Kristus. ${ }^{38}$ Allah berinisiatif berdamai dengan manusia berdosa. Damai sejahtera Kristus ada di dalam diri Orang Percaya. Kerajaan Allah adalah soal kebenaran dan damai sejahterah (Rm. 14: 17; 1Kor. 12:27). Cara untuk memelihara damai sejahtera di dalam hati dengan bersyukur dan menghindarkan sikap iri hati. ${ }^{39}$

Prinsip damai sejahtera pertama: dimana ada kekudusan disitu ada damai sejahtera. Ibrani 12: 14 menjelaskan bahwa damai sejahtera tidak dapat dipisahkan dari kebenaran atau kekudusan. Kedua, damai Sejahtera hanya ada di dalam Kristus. Inti dari damai sejaterah yang diberikan Tuhan adalah hidup kekal dan keselamatan yang kekal. Damai sejahtera Allah memberikan beberapa manfaat, pertama damai sejahtera menandakan adanya perlindungan dan pemeliharaan Tuhan (Im. 26: 6; Yes. 26: 3). Kedua, damai sejahtera menandakan Allah akan turut bekerja untuk mendatangkan kebaikan dalam hidup ( Yes. 26: 12). Ketiga, damai sejahtera menunjukkan berkat Allah (Zak. 8: 11-12). Keempat, damai sejahtera menunjukkan penyertaan Allah (2 Kor. 13: 11).

\section{Mengenakan Perkataan Kristus}

Mengenakan perkataan Kristus adalah prinsip penting untuk mengelola

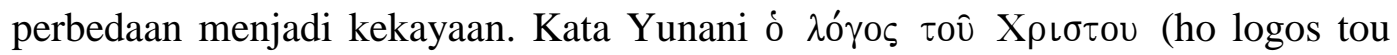
christou). Logos diterjemahkan Firman (Yoh. 1: 1), Kolose 3: 16 menyatakan

${ }^{38}$ Murray J. Harryis, Colossians \& Philemon (Michigan: Grand Rapids, 1991), 165. 401.

39 Henry, Tafsiran Surat Galatia, Efesus, Filipi, Kolose, 1 dan 2 Tesalonika, 1 dan 2 Timotius, 400- 
firman Tuhan diam diantara orang percaya. Ayat 15 dalam bahasa Yunani

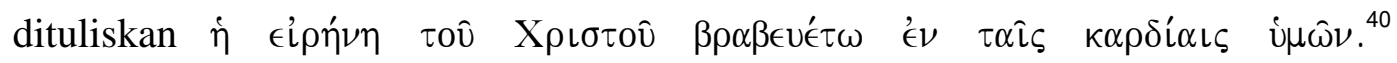
Penekanan yang dimaksud adalah pada pribadi dan karya Kristus. ${ }^{41}$ Dengan demikian damai sejahtera di dalam Firman harus memerintah dan tinggal ditengah-tengah jemaat Kolose yang memiliki perbedaan-perbedaan pendapat, latar belakang dan budaya. Inilah salah satu teori dalam mengelola perbedaan menjadi sebuah kekayaan dunia yang multikultural.

Tuhan menghendaki orang percaya tidak hanya mendengar, membaca dan mengetahui firman Tuhan, namun firman Tuhan dengan segala kekayaan harus benar-benar tinggal dan menetap di dalam hati setiap orang percaya. Firman Tuhan memberikan kekayaan kekayaan spiritual dan pengetahuan dalam bersosialisasi, bermasyarakat, mengajar dan menegur. ${ }^{42}$ Tuhan menghendaki manusia menunjukkan respon kepada firman Tuhan. Kata 'diam' dalam teks Yunani enoiko berarti dwell in one and influence him or her. Pemahaman 'diam' tidak dalam arti pasif tetapi aktif dan mempengaruhi orang percaya untuk maksud baik.

Tujuan mengenakan perkataan Kristus adalah untuk menjadi penyambung lidah-Nya (Kol. 3:16). Firman yang telah tinggal dan memengaruhi hidup orang percaya, selanjutnya akan membuat orang percaya mempengaruhi hidup orangorang di sekelilingnya melalui pengajaran, teguran, mazmur dan pujian. Perkataan Tuhan yang telah menjadi bagian dalam pengalaman rohani dapat mengarahkan segala pikiran, perkataan, perbuatan, dan motivasi orang percaya. Dengan demikian pada waktu mengajar dan memberikan teguran firman Tuhanlah yang

40 O'Brien, World Biblical Commentary Colossians, 206.

${ }^{41}$ O'Brien, 206

42 Dunn, The Epistles to the Colossians and to Philemon: A Commentary on the Greek Text, 237. 
disampaikan. Demikian juga pada waktu menaikkan mazmur dan puji-pujian sudah pasti memuliakan nama Tuhan. Manfaat perkaaan Kristus tinggal di dalam memberikan hikmat saat bermasyarakat, mengajar, menegur, menasehati dan menyanyikan mazmur pujian.

\section{KESIMPULAN}

Mengelola perbedaan menjadi sebuah kekayaan di tengah keluarga, gereja dan bangsa harus dimulai dengan masing-masing orang menerima Yesus Kristus sebagai Tuhan dan Juruselamat dunia. Setiap orang harus menjadi manusia baru berdasarkan anugerah Tuhan. Setelah menjadi manusia baru, oleh pertolongan Roh Kudus setiap orang dimampukan menerapkan prinsip-prinsip kebenaran yang telah dipaparkan Paulus dalam Kolose 3: 12-17 yakni: mengenakan belas kasihan, mengenakan kemurahan, mengenakan kerendahan hati, mengenakan kelemahlembutan, mengenakan kesabaran, mengenakan pengampunan, memerintah dengan damai sejahtera dan mengenakan perkataan Kristus. Prinsipprinsip kebenaran tersebut menghasilkan inovasi yang baru, ide yang satu dan saling melengkapi sehingga terwujud kekayaan dari sebuah perbedaan.

\section{KEPUSTAKAAN}

Anthony, Hoekma. Diselamatkan oleh Anugrah. Surabaya: Momentum, 2011.

Barclay, William. Pemahaman Alkitab Setiap Hari, Surat Filipi, Kolose, 1 dan 2 Tesalonika. Jakarta: BPK Gunung Mulia, 2006.

Bratcher, Robert G., dan Eugene A. Penafsiran Alkitab: Surat-surat Paulus kepada Jemaat di Kolose dan Filemon. Jakarta: LAI, 2014.

Dunn, J.D.G. The Epistles to the Colossians and to Philemon: A Commentary on the Greek Text. The new international Greek Testament commentary. W.B. https://books.google.co.id/books?id=j3F0oypUqZoC. 
End, Van den. Ragi Carita. Jakarta: BPK Gunung Mulia, 2006.

Guthrie, Donald. Teologi Perjanjian Baru. Vol. 3. Jakarta: BPK Gunung Mulia, 2009.

Harryis, Murray J. Colossians \& Philemon. Michigan: Grand Rapids, 1991.

Henry, Matthew. Tafsiran Surat Galatia, Efesus, Filipi, Kolose, 1 dan 2 Tesalonika, 1 dan 2 Timotius, . Surabaya: Momentum, 2015.

Jong, Christian De. Menuju Kesaan Gereja. Jakarta: BPK Gunung Mulia, 2006.

Karnavian, Tito. Top Secret Membongkar Konflik Poso. Jakarta: Gramedia, 2008.

Kurniawan, Jimmi. "Kajian Eksegetikal Tentang Kelahiran Baru Menurut Yohanes 3:1-8." Jurnal Teologi Gracia Deo 1, no. 1 (Juni 2018): 1-13. http://sttbaptisjkt.ac.id/ejournal/index.php/graciadeo/article/viewFile/17/7.

Lee, Witness. Pelajaran Hayat Kolose. Vol. 2. Yayasan Perpustakaan Injil Indonesia (Yasperin), 2020.

O'Brien, Peter T. World Biblical Commentary Colossians. Texas: Word Books Publisher, 2011.

Penyusun, Tim. Membangun Kedaulatan Bangsa Berdasarkan Nilai-nilai Pancasila: Pemberdayaan Masyarakat Dalam Kawasan Terluar, Terdepan, dan Tertinggal. Yogyakarta: Pusat Studi Pancasila, 2015.

Sipayung, Hendra. Menantu VS Mertua, Trik Ampuh membina hubungan baik antara menantu dan Mertua. Jakarta: Gramedia, 2010.

Thatcher, Margareth. Buku Infestasi bagi Kaum Perempuan. Jakarta: Gramedia, 2007.

Tim Pustaka Phoenix. Kamus Besar Bahasa Indonesia. Jakarta: Media Pustaka Phoenix, 2009.

Trench, Richard Chenevix. Synonyms Of The New Testament. London: Ted Hildebrant, 2006.

Wangyu Wangyu, dan Robi Panggarra. "Konsep Eirene Berdasarkan Efesus 2:1122 Dan Implementasinya Dalam Kekristenan Masa Kini." Jurnal Jaffray 8, no. 2 (1 Oktober 2010): 86-105. 